\title{
Utilization of silkworm cocoon waste as a sorbent for the removal of oil from water
}

\author{
Hiroshi Moriwaki*, Shiori Kitajima, Masahiro Kurashima, Ayaka Hagiwara, Kazuma \\ Haraguchi, Koji Shirai, Rensuke Kanekatsu and Kenji Kiguchi
}

${ }^{1}$ Shinshu University, Faculty of Textile Science and Technology, Division of Applied Biology, 3-15-1, Tokida, Ueda 386-8567, Japan, E-mail: moriwaki@shinshu-u.ac.jp

* To whom correspondence should be addressed.

E-mail: moriwaki@shinshu-u.ac.jp

\begin{abstract}
The aim of this study is to investigate the utilization of silkworm cocoon waste, such as pierced or stained cocoons, as a sorbent material for the removal of motor and vegetable oils from water. The oil-sorption capacity, rate and reusability of the material were evaluated. The results show the high sorption capacity of the silkworm cocoon waste sorbent (42-52 $\mathrm{g}_{\text {oil }} / \mathrm{g}_{\text {sorbent }}$ for motor oil and 37- $60 \mathrm{~g}$ oil $/ \mathrm{g}_{\text {sorbent }}$ for vegetable oil). The oil sorbed onto the material could be recovered by squeezing the sorbent, and the squeezed material showed an oil sorption capacity over $15 \mathrm{~g}_{\mathrm{oil}} / \mathrm{g}_{\text {sorbent }}$. We concluded that the material shows a high performance as a low-cost and environmental friendly sorbent for the removal of oil from water.
\end{abstract}

Key words: silkworm cocoon waste, oil-sorbent

\section{Introduction}

The environmental pollution of water by oil has been a specific and serious problem $(1,2)$. An oil spill in the environment causes adverse effects on wildlife and loss of oil, therefore, it is important to establish and develop techniques of oil removal from the water environment in order to apply the 
appropriate procedure to the cleanup of the oil pollution. The use of an oil sorbent is the commonly used technique to remove oil from the environment (3-8). Recently, the application of natural fibers, such as cotton (9), cotton grass fiber (10), milkweed, kenaf (11), vegetable fibers (12) and wool (13, 14), as the material for the removal of oil has been studied, and some of them showed higher oil sorption capacities for oil than the typical synthetic oil sorbent made of polypropylene. Natural oil sorbent fibers are environmentally friendly materials, because of their biodegradability and reusability. This feature makes natural fibers very attractive as oil sorbents compared to synthetic fibers.

In this study, we investigated the utilization of silkworm cocoon waste as a low cost sorbent for the removal of oil from water. In general, the silkworm cocoon is expensive. However, most of the pierced cocoons or very dirty cocoons of the silkworm are discarded as industrial wastes, and can be obtained as a low cost material. The silkworm cocoon has the property of a slow biodegradability (15), and the shell of the silkworm cocoon contains wax and shows hydrophobic property (16) which are important preconditions for an efficient oil sorbent (17). Based on these facts, there is the possibility that the silkworm cocoon waste acts as a high-performance material for the sorption of oil. The silkworm cocoon waste without removal of sericin was milled, and the obtained flocculate material (Figure 1 b)) was used as a sorbent for oil in this study. The oil-sorption capacity, rate and reusability of the silkworm cocoon waste sorbent (SCWS) were investigated.

\section{Experimental}

\section{Sorbent material made of silkworm cocoon waste (SCWS)}

The pierced silkworm cocoon of a commercial silkworm strain was used for the preparation of the SCWS. The pierced silkworm cocoons arise from the silk industry at the passage of the silkworm. The pierced cocoons of silkworms bred at Shinshu University were used (Figure 1 a)). The silkworm cocoon waste was dried according to the normal procedure using a cocoon drier (the temperature was programmed at $110^{\circ} \mathrm{C}$, then decreased to $60{ }^{\circ} \mathrm{C}$ at the rate of $-0.14{ }^{\circ} \mathrm{C} / \mathrm{min}$.). The dried pierced silkworm cocoon was cut by scissors into small pieces (about $5 \times 5 \mathrm{~mm}$ ). The fractions were milled by a compact crusher (Force Mill, Osaka Chemical Co. Ltd., Osaka, Japan) for 1 minute. The obtained flocculate of silk fibers (Figure 1 b)) was used as a sorbent for the removal of oil from water.

For the evaluation of buoyancy of the sorbent, tests were performed by the method based on the procedure described in the literature ${ }^{18}$. Ten gram of the sorbent was placed in a basket containing a mesh bottom with $1 \mathrm{~mm}$ openings. Then, the basket was lowered into a dish filled with water to a depth of $8 \mathrm{~cm}$ for 15 minutes. At the end of the test, the buoyancy of the sorbent was observed.

\section{Material}

Motor oil (Toyota castle mineral oil SL-10W-30) was obtained from the Toyota Motor Corporation (Aichi, Japan). Vegetable oil (colza oil) was purchased from CGC Japan (Tokyo, Japan). It is a mixture of saturated $(6 \%)$ and unsaturated $(94 \%)$ fatty acids. The viscosities of the oils at $20^{\circ} \mathrm{C}$ were measured by a viscometer DV-II + Pro (Brookfield, Massachusetts, USA). The characteristics of the investigated oils are listed in Table 1. One gram of oils in petri dish were place for 24 hours and 10 days at room temperature. Then, the weight of oil loss was measured by an analytical balance. Sodium chloride was purchased from Wako Pure Chemical Industries, Ltd. (Osaka, Japan). The distilled water $(\mathrm{pH}=7-8)$ was produced by an automatic water distillation apparatus (NANOpure II, Barnstead, Boston, Massachusetts, USA). Marine water was sampled at the offing of the Miura Peninsula in Japan. The salinity of the water was $29.2 \%$. Natural wool fiber was obtained from sheep (Suffolk) bred at Shinshu University.

\section{Oil-sorption tests}

For the sorption experiments, ten gram of the motor and vegetable oils were poured into a beaker containing $100 \mathrm{~mL}$ of distilled or marine water. Thereafter, $0.1 \mathrm{~g}$ of the SCWS was gently placed on the oil surface. After 10 minutes, the material was removed using forceps and drained for 1 minute. The material sorbed oil placed on a petri dish and then dried for 24 hours at room temperature (26-30 $\left.{ }^{\circ} \mathrm{C}\right)$. The weight of the oil-sorbed material dried for 24 hours was not changed compared to that dried for 10 days at room temperature. Therefore, the period for drying was set for 24 hours. After drying, the oil-sorbed material was weighed by an analytical balance $(0.001 \mathrm{~g})$. Tests were carried 
out with and without stirring. In the case of stirring (dynamic system), the beakers were placed on a shaker (MK200D, Yamato, Tokyo, Japan).

The sorption capacity was determined according to the following equation:

$$
\mathrm{q}=\left(\mathrm{S}_{\mathrm{t}}-\mathrm{S}_{0}\right) / \mathrm{S}_{0}
$$

where $\mathrm{q}$ is the sorption capacity $\left(\mathrm{g}_{\mathrm{oil}} / \mathrm{g}_{\text {absorbant }}\right), \mathrm{S}_{\mathrm{t}}$ is the total mass of the sorbed samples $(\mathrm{g})$ and $\mathrm{S}_{0}$ is the initial mass of the sorbed materials.

For the reusability test of the material, ten grams of the motor and vegetable oils was poured into a beaker containing $100 \mathrm{~mL}$ of distilled water, and then $0.1 \mathrm{~g}$ of the SCWS was placed on the oil surface. Five cycles of the sorption process were performed for each sample. Between the each cycle, material was squeezed, and weighed. The recovery of oil was calculated by division of the difference between the oil-sorbed material and the material after squeezing by the initial quantity of the sorbed oil.

\section{Results and Discussion \\ Removal of oil from water by SCWS}

The sorbent material made of silkworm cocoon waste (SCWS) showed a water-repellent nature (Figure 1 c)), and floated on the water. The buoyancy tests showed, after 15 minutes in distilled and marine water, that the majority of the material remained at the surface of water and there was no much of settling of the sorbent under both static and dynamic conditions. By placing SCWS on the oil surface, the material sorbed oil and changed from a flocculent fiber to a gelatinous semisolid (Figure $1 \mathbf{~ d}$ )). The results of the oil removal by the SCWS from distilled water containing $10 \mathrm{~g}$ of the motor and vegetable oil are shown in Figure 2. The sorption rate of the motor oil and the vegetable oil by the SCWS were not significantly different. The use of the sorption process over 10 min has no significant influence on the sorption of the oils, therefore, the sorption time was set at 10 minutes. The removal (\%) of the motor oil and vegetable oil from distilled or marine water by the SCWS and the natural wool fiber are shown in Table 2. The material $(0.1 \mathrm{~g})$ removed over $50 \%$ of the $10 \mathrm{~g}$ of the oils on the water. On the other hand, the natural wool fiber removed less than $20 \%$ of the $10 \mathrm{~g}$ of the oils in the water. The result showed that the higher performance of the SCWS as an oil sorbent compared to the natural wool fiber. In addition, the removal (\%) of the oils from the marine water by the SCWS was the same level as in the case of the removal from distilled water. This result indicates that the SCWS could be used for oil removal not only from fresh water, but also from marine water. There was a tendency that the values of the oil removal (\%) under dynamic system were lower than those under static system (Table 2, entry 1-8). The difference would be caused by the formation of slurry from a part of SCWS with oil.

Figure 3 shows the removal of oil from water vs. the weight of the silkworm cocoon waste. The 0.20 grams of the SCWS removed over $70 \%$ of the $10 \mathrm{~g}$ of the oils added on the water. For the $10 \mathrm{~g}$ of added oils, the sorption capacities ( $\mathrm{g}_{\mathrm{oil}} / \mathrm{g}_{\text {sorbent }}$ ) vs. weight of the silkworm cocoon waste are shown in Figure 4. The sorption capacities of the SCWS were 42-52 $\mathrm{g}_{\text {oil }} / \mathrm{g}_{\text {sorbent }}$ for the motor oil and 37- 60 $\mathrm{g}_{\text {oil }} / \mathrm{g}_{\text {sorbent }}$ for the vegetable oil. Though we could not simply compare the performance of the SCWS as an oil sorbent to those of the other oil sorbent because of the difference in the used oil, the values of the oil capacities of the SCWS are higher than those of the other sorbent previously reported (Table 3). These results would be due to the high hydrophobicity and buoyancy of the SCWS.

\section{Reusability of SCWS}

The reusability of SCWS and the recovery of the sorbed oil are summarized in Table 4. The recoveries of the motor and vegetable oils were both over $90 \%$. The oil sorption capacities for the second cycle were approximately $40 \%$ of those for the first cycle with the values at the high levels of 22 and $18 \mathrm{~g}_{\text {oil }} / \mathrm{g}_{\text {sorbent }}$ for the motor and vegetable oils, respectively.

Further repeating of the sorption cycle (1-5 times) decreased the oil capacities of the SCWS (Figure 5). The decrease in the oil sorption of the SCWS by repeating the sorption treatment would be due to the decrease in the surface area of the SCWS by the aggregation of the oil between the fibers. Furthermore, there is a possibility that the denaturation of the surface protein of the SCWS by contact with the oil caused the decrease in the oil sorption capacity. However, after five sorption cycles, the sorption capacities were over $15 \mathrm{~g}_{\mathrm{oil}} / \mathrm{g}_{\text {sorbent }}$.

In summary, the advantages of the SCWS as an oil-sorbent are as follows: 
1) The preparation of the SCWS is very simple, and the material is low cost.

2) The SCWS has a slow biodegradable.

3) The SCWS has a high sorption capacity for oil because of the high hydrophobic property of the material.

4) The oil sorbed on the material could be recovered, and the SCWS material can be reused as an oil removal sorbent, which shows the sorption capacity over $15 \mathrm{~g}_{\text {oil }} / \mathrm{g}_{\text {sorbent }}$.

Based on these points, it is concluded that the SCWS is an effective and low cost sorbent for the removal of oil from water.

\section{Acknowledgements}

This work was supported by a Grant-in-Aid for the Global COE Program by the Ministry of Education, Culture, Sports, Science, and Technology. The authors wish to thank Prof. K. Hanabusa and Ms. H. Hoshizawa (Shinshu University) for their generous support of the measurements of the oil sample viscosities. The authors also wish to thank Mr. H. Fukushima and Ms. A. Tamura (Shinshu University) for their fruitful discussions about this research. We thank Dr. Tohru Moriyama and Mr. Seiji Chino (Shinshu University) for their kind supply of the marine water and natural wool fiber, respectively.

\section{Literature Cited}

(1) J. Whitfield, How to clean a beach, Nature 422 (2003) 464-466.

(2) C. Alonso-Alvarez, C. Pérez, A. Velando, Effects of acute exposure to heavy fuel oil from the Prestige spill on a seabird, Aqua. Toxicol. 84(1) (2007) 103-110.

(3) Q. F. Wei, R. R. Mather, A. F. Fotheringham, R. D. Yang, Evaluation of nonwoven polypropylene oil sorbents in marine oil-spill recovery, Marine Pollut. Bull. 46 (2003) 780-783.

(4) R. F. Johnson, T. G. Manjrekar, Removal of oil from water surfaces by sorption on unstructured fibers, Environ. Sci. Technol. 7 (1973) 439-443.

(5) V. Rajaković-Ognjanović, G. Aleksić, L. Rajaković, Governing factors for motor iol removal from water with different sorption materials, J. Hazard. Mater. in press.

(6) A. Gammoun, S. Tahiri, A. Albizane, M. Azzi, J. Moros, S. Garrigues, M. de la Guardia, Separation of motor oils, oily wastes and hydrocarbons from contaminated water by sorption on chrome shavings, J. Hazard. Mater. 145 (2007) 148-153.

(7) Ch. Teas, S. Kalligeros, F. Zanikos, S. Stournas, E. Lois, G. Anastopoulos, Investigation of the effectiveness of absorbent materials in oil spill clean up, Desalination 140 (2001) 259-264.

(8) S. A. Sayed, A. M. Zayed, Investigation of the effectiveness of some adsorbent materials in oil spill clean-ups, Desalination 194 (2006) 90-100.

(9) G. Deschamps, H. Caruel, M.-E. Borredon, C. Bonnin, C. Vignoles, Oil removal from water by selective sorption on hydrophobic cotton fibers. 1. Study of sorption properties and comparison with other cotton fiber-based sorbents, Environ. Sci. Technol. 37 (2003) 1013-1015.

(10)S. Suni, A.-L. Kosunen, M. Hautala, A. Pasila, M. Romantschuk, Use of a by-product of peat excavation, cotton grass fibre, as a sorbent for oil-spills, Marine Pollut. Bull. 49 (2004) 916-921.

(11)H-M. Choi, R. M. Cloud, Natural sorbents in oil spill cleanup, Environ. Sci. Technol. 26 (1992) 772-776.

(12)T. R. Annunciado, T. H. D. Sydenstricker, S. C. Amico, Experimental investigation of various vegetable fibers as sorbent materials for oil spills, Marine Pollut. Bull. 50 (2005) 1340-1346.

(13)M. M. Radetic, D. M. Jocic, P. M. Jorancic, Z. L. Petrovic, H. F. Thomas, Recycled wool-based nonwoven material as an oil sorbent, Environ. Sci. Technol. 37 (2003) 1008-1012.

(14)M. Radetic, V. Ilic, D. Radojevic, R. Miladinovic, D. Jocic, R. Jovancic, Efficiency of recycled wool-based nonwoven material for the removal of oils from water, Chemosphere 70 (2008) $525-530$.

(15) N. Minoura, M. Tsukada, M. Nagura, Physico-chemical properties of silk fibroin membrane as a biomaterial, Biomaterials 11(6) (1990) 430-434.

(16) K. Komatsu, Chemical studies on cocoon wax (I) Analysis of cocoon wax by means of infrared spectrometry, Bull. Sericul. Exp. Sta. 23(5) (1969) 499-512.

(17)T. T. Lim, X. Huang, Evaluation of kapok (Ceiba pentandra (L.) Gaertn.) as a natural hollow 
hydrophobic-oleophilic fibrous sorbent for oil spill cleanup, Chemosphere 66(5) (2007) 955-963.

(18) T. H. Ribeiro, R. W. Smith, J. Rubio, Sorption of oils by the nonliving biomass of a Salvinia sp., Environ. Sci. Technol. 34 (2000) 5201-5205.

\section{Figure captions}

Fig.1 Pictures of the silkworm cocoon waste sorbent. a) silkworm cocoon waste, b) sorbent made of silkworm cocoon waste $(0.1 \mathrm{~g}), \mathrm{c})$ water and the silkworm cocoon waste sorbent, d) oil-sorbed material (motor oil) after drying for 24 hours at room temperature.

Fig.2 Oil-sorption rates of the silkworm cocoon waste sorbent (100mg). Oil-sorption rates are shown as the removal of oil from water (\%) as a function of time in minutes. The quantity of the oils added on the water is $10 \mathrm{~g}$. $\circ$; Motor oil, $\bullet$; Vegetable oil.

Fig.3 Removal of oil from water (\%) vs. weight of the silkworm cocoon waste. The quantity of the oils added on the water is $10 \mathrm{~g}$. The sorption time was 10 minutes. ○; Motor oil, $\diamond$; Vegetable oil.

Fig.4 Sorption capacities $\left(\mathrm{g}_{\mathrm{oii}} / \mathrm{g}_{\text {sorbent }}\right)$ vs. weight of the silkworm cocoon waste. The quantity of the oils added on the water was $10 \mathrm{~g}$. The sorption time was 10 minutes. $\bigcirc$; Motor oil, $\diamond$; Vegetable oil. Fig. 5 Reusability of silkworm cocoon waste sorbent for the removal of oil from water.

\section{Table 1 Characteristics of the investigated oils}

\begin{tabular}{cccc}
\hline Sample & $\begin{array}{c}\text { Viscosity }^{a} \\
(\mathrm{cP})\end{array}$ & $\begin{array}{c}\text { Density } \\
\left(\mathrm{g} / \mathrm{cm}^{3}\right)\end{array}$ & $\begin{array}{c}\text { Weight loss }(\%) \\
\text { after } 24 \mathrm{~h}\end{array}$ \\
\hline Motor oil & 130 & 0.84 & 0.0 \\
Vegetable oil & 59 & 0.88 & 0.0 \\
\hline The viscosities of oils at shear rate $13.05 \mathrm{~s}^{-1 .}$ &
\end{tabular}

Table 2 Removal of motor oil and vegetable oil by silkworm cocoon waste and adsorbent cotton

\begin{tabular}{ccccc}
\hline Sorbent & Oil & Oil quantity $(\mathrm{g})$ & Removal $(\%)$ & Standard deviation $^{\mathrm{b}}$ \\
\hline SWCW & Motor oil & $1.5^{\mathrm{a}}$ & 99 & 0.51 \\
& Motor oil & $10^{\mathrm{a}}$ & 84 & 2.6 \\
& Vegetable oil & $1.5^{\mathrm{a}}$ & 100 & 0.17 \\
& Vegetable oil & $10^{\mathrm{a}}$ & 86 & 5.7 \\
& Motor oil & $10^{\mathrm{c}}$ & 85 & 4.6 \\
& Vegetable oil & $10^{\mathrm{c}}$ & 82 & 5.9 \\
\hline \multirow{2}{*}{ cotton } & Motor oil & $1.5^{\mathrm{a}}$ & 30 & 12 \\
& Vegetable oil & $1.5^{\mathrm{a}}$ & 14 & 6.5 \\
\hline
\end{tabular}

\footnotetext{
${ }^{a}$ The amount of the used sorbent was $100 \mathrm{mg}$. Oil was mixed with $100 \mathrm{~mL}$ of distilled water.

The sorption time was 10 minutes.

${ }^{\mathrm{b}} \mathrm{n}=3$.

${ }^{\mathrm{c}}$ Oil was mixed with $100 \mathrm{~mL}$ of $\mathrm{NaCl}(3.5 \%)$ aqueous solution.
} 
Table 3 Oil sorption capacity of various sorbents

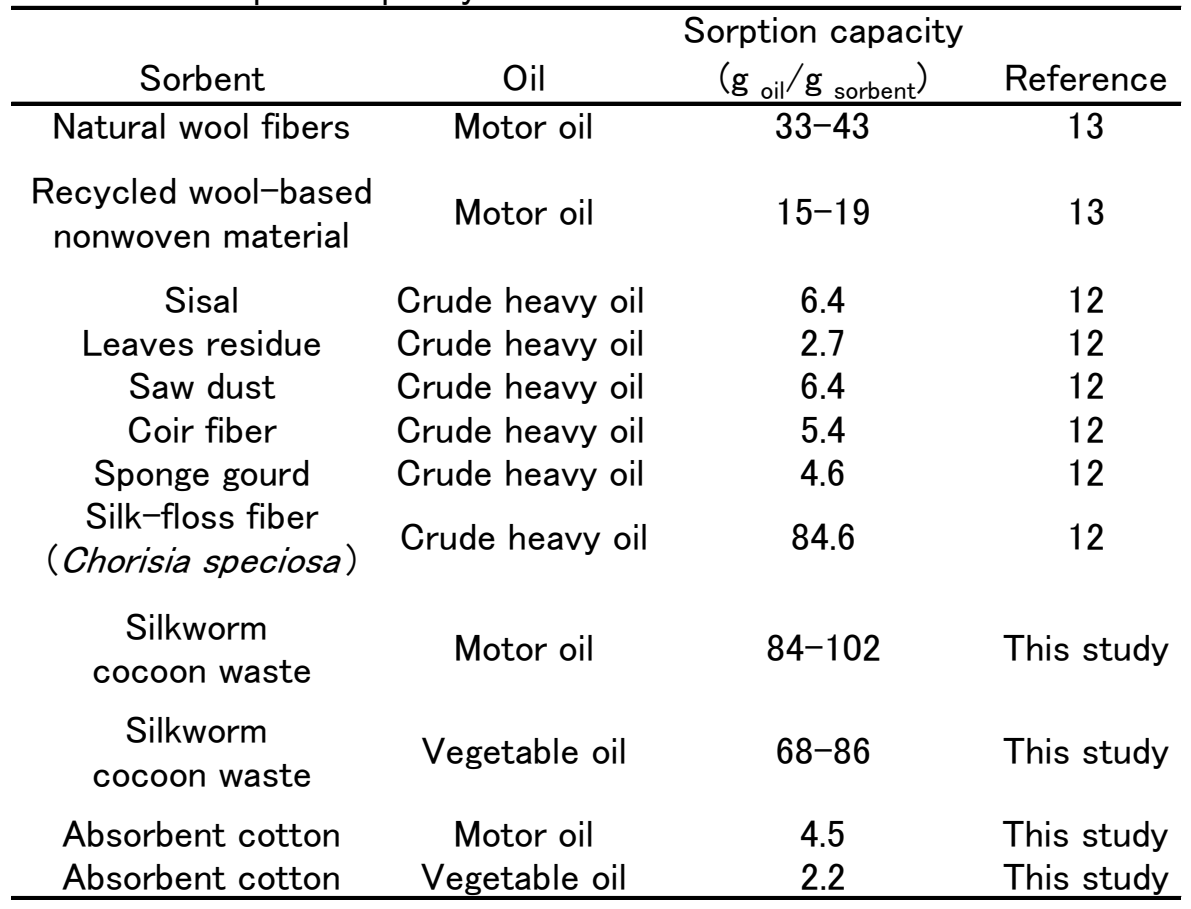

Table 4 Sorption capacity of the waste of silkworm cocoon for oils along two sorption cycles

\begin{tabular}{|c|c|c|c|}
\hline \multirow[b]{2}{*}{ Oil } & \multicolumn{2}{|c|}{ Sorption capacity ( $\left.\mathrm{g}_{\text {oil }} / \mathrm{g}_{\text {sorbent }}\right)^{\mathrm{a}}$} & \multirow{2}{*}{$\begin{array}{l}\text { The quantity of } \\
\text { recovered oil }(\mathrm{g})^{\mathrm{c}, \mathrm{c}}\end{array}$} \\
\hline & First cycle & Second cycle & \\
\hline Motor oil & $84 \pm 2.6$ & $66 \pm 3.4(79)^{b}$ & $8.4 \pm 0.26(100)$ \\
\hline Vegetable oil & $85 \pm 4.4$ & $62 \pm 5.8(73)$ & $8.5 \pm 0.44(100)$ \\
\hline
\end{tabular}

\footnotetext{
${ }^{a}$ The quantity of the sorbent (silkworm cocoon waste) was $100 \mathrm{mg}$. The sorption time was $10 \mathrm{~min}$. Oil quantity was $10 \mathrm{~g}$. Calculated according to the equation 1.

The values are the average and standard deviation $(n=4)$.

${ }^{b}$ The values in parentheses are the percentage of the sorption capacity at the second cycle against it at the first cycle.

${ }^{c}$ The values are the quantity $(\mathrm{g})$ of the oil obtained by squeezing the oil-sorbed material.

${ }^{d}$ The values in parentheses are the percentage of the quantity of the recovered oil against the quantity of the oil sorbed on the material.
} 
a)

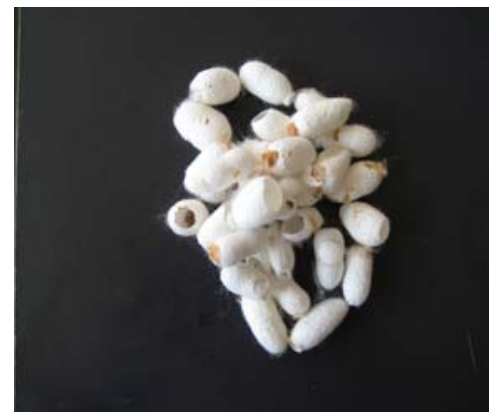

b)

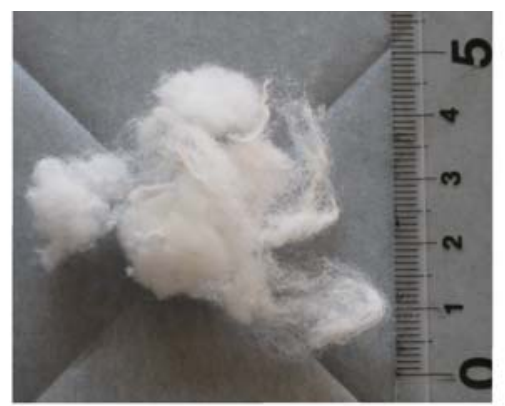

c)

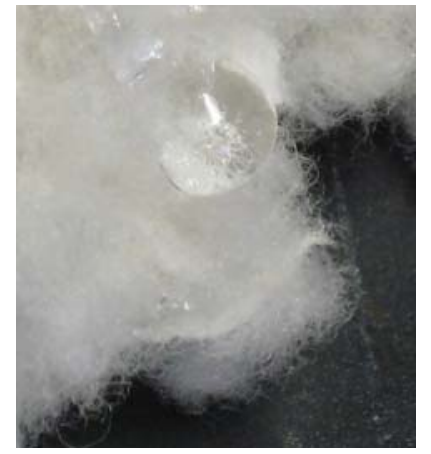

d)

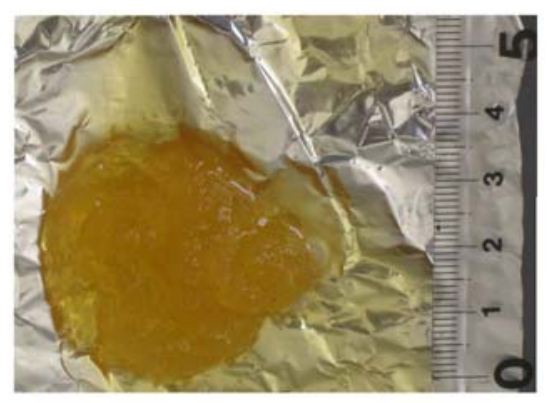

Fig.1 


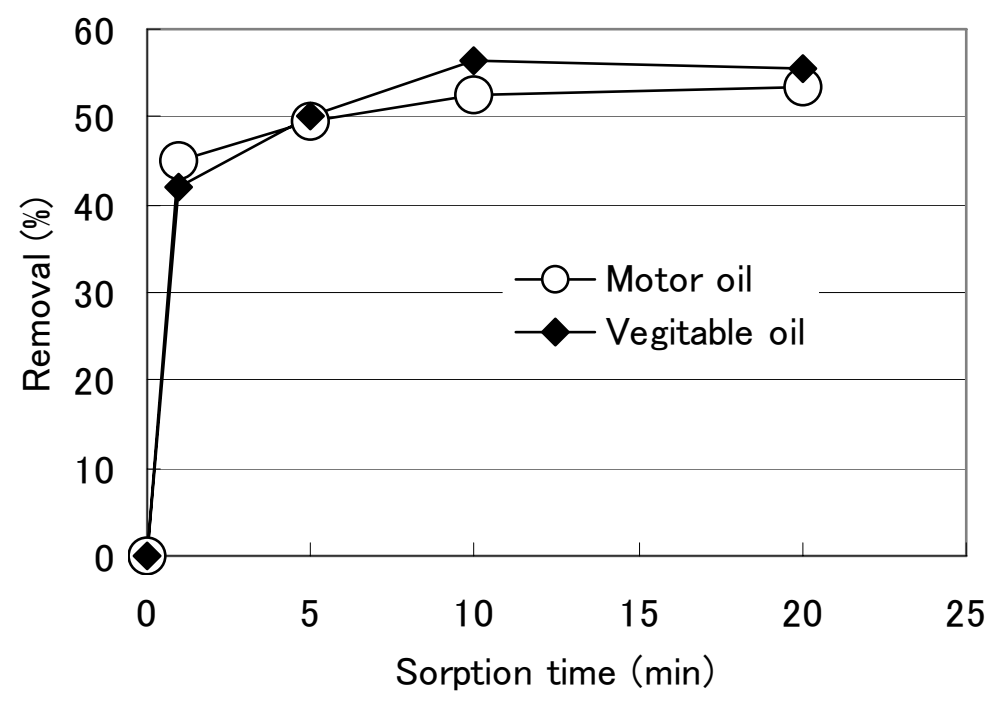

Fig.2

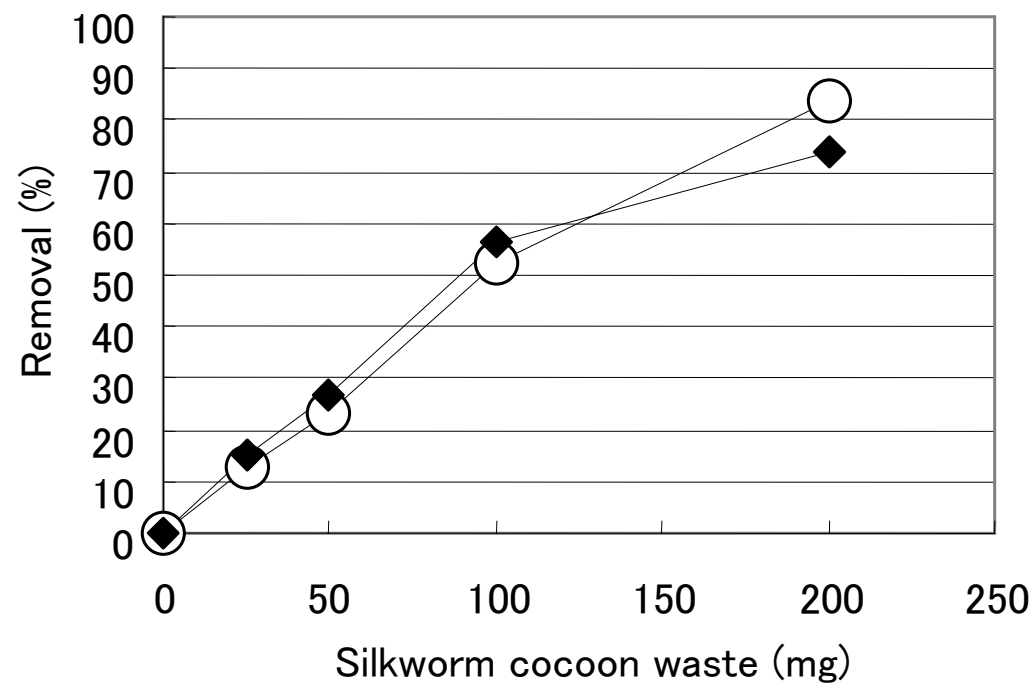

Fig.3 


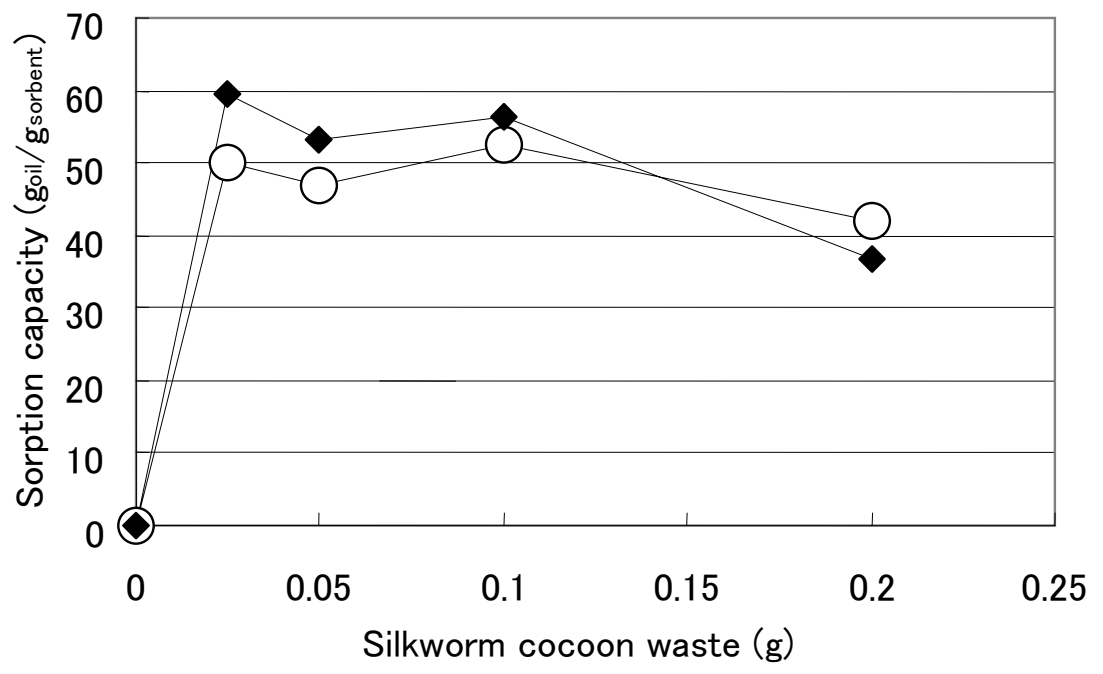

Fig.4

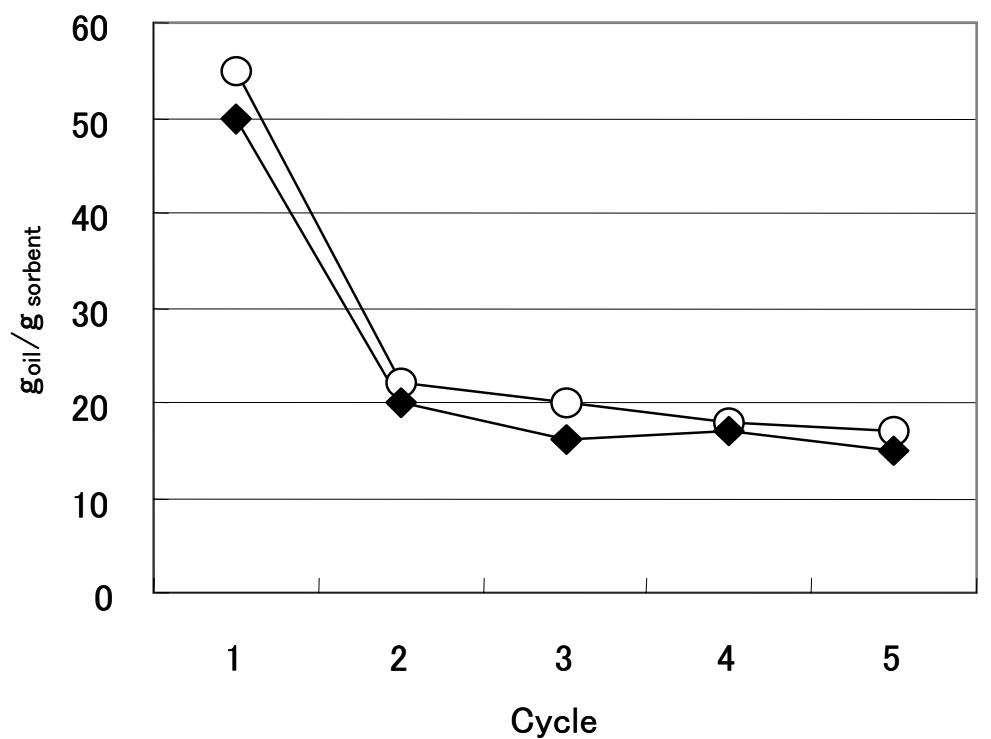

Fig.5 